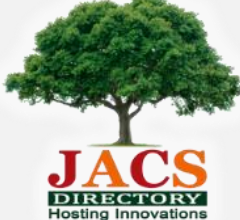

Journal of Nanoscience and Technology

\title{
Acute Toxicity Study of Silver Nanoparticle Coupled with Euphorbia thymifolia
}

\author{
Srimoyee Saha ${ }^{1}$, Niranjan Bala², Ruma Basu ${ }^{3}$, Sukhen Das ${ }^{1, *}$ \\ ${ }^{1}$ Department of Physics, Jadavpur University, 188, Raja Subodh Chandra Mullick Road, Jadavpur, Kolkata - 700 032, West Bengal, India. \\ ${ }^{2}$ Department of Botany, Sreegopal Banerjee College, Bagati, Mogra, Hoogly - 712 503, West Bengal, India. \\ ${ }^{3}$ Department of Physics, Jogamaya Devi College, Kolkata - 700 026, West Bengal, India.
}

\section{A R T ICLE DETAILS}

\section{Article history:}

Received 20 May 2018

Accepted 08 June 2018

Available online 13 June 2018

\section{Keywords:}

Acute Toxicity

Nanomedicine

Euphorbia thymifolia

Mice Model

\begin{abstract}
A B S T R A C T
Nanomedicine is widely explored nowadays for treatment of life threatening diseases, yet comes with various challenges and questions. The present study encapsulates the acute toxicological aspects of the Euphorbia thymifolia coupled silver nanoparticles (ET-Ag NP). For acute toxicity studies according to OCED (Organization for Economic Cooperation Development) guidelines Swiss Albino mice (6-8 weeks) were used and were given single intraperitoneal dose of 2000 and $5000 \mathrm{mg} / \mathrm{kg}$ body weight and were observed for mortality and other side effects for 14 days. The individual components of the formulation, viz. silver oxide in surface modified nano form and at low dose, and Euphorbia thymifolia are both biocompatible materials. No changes were found for general appearance, behavior and body weight, thus concluding that the nanocomposite formulation does not have single dose toxicity.
\end{abstract}

\section{Introduction}

Nanomedicines have been acclaimed as the boon of the medicinal world. The applications of Nanomedicines have been far and widespread $[1,2]$. From the development of diagnostic devices [3], analytical tools [4], physical therapy applications $[3,5]$ to therapeutic drug delivery [4-6], and targeted drug delivery [5].

In vivo, nanoparticles will be translocated to and entrapped in other tissues or organs along the blood circulation. The small size and large surface area endow them with enhanced activity along with possible intrinsic toxicity. Toxicity indicates the adverse effects due to the interaction between nanomaterials and cells. Even at a very small cellular level, they may pose potential long-term health hazards [7]. The evaluation of toxic properties of nanomaterials is crucial when considering them for use in biomedical science. In practice, the evaluation typically includes acute, subchronic, and chronic studies [8]. The current status of toxicology due to nanoparticles has been reported by Becker [9-12].

The toxic effects of chemicals, food substances, pharmaceuticals, etc., have attained great significance in the $21^{\text {st }}$ century. Toxicity tests are mostly used to examine specific adverse events or specific end points such as cancer, hepatotoxicity, abnormal toxicity and skin/eye irritation [13, 14]. Toxicity testing also helps calculate the No Observed Adverse Effect Level (NOAEL) dose and is helpful for clinical studies. Organisation for Economic Co-operation and Development (OECD) and the International Conference on Harmonization (ICH) brought out the guidelines for toxicity testing of pharmaceutical substances [15].

During our work, we have synthesized Ag NP via green routes using Euphorbia thymifolia whole plant extract. Optical properties of the synthesized NPs were measured using UV-visible (UV-VIS) spectroscopy. Morphology of the prepared samples was analyzed by field emission scanning electron microscopy (FESEM).The present work evaluates the toxicity of the prepared samples and ensures their safety upon experimental mice model and also analyzes their behavioural changes if any upon their in vivo application.

\section{Experimental Methods}

\subsection{Materials}

Euphorbia thymifolia was collected from Jadavpur University campus. Swiss albino mice (6-8 weeks old) weighing $32 \pm 5 \mathrm{~g}$ were procured from a CPCSEA registered animal house to conduct the acute toxicity study.

\subsection{Plant Extract Preparation}

About $1 \mathrm{~g}$ of ET leaves were washed thoroughly with plenty of distilled water and both surfaces of leaves were sterilized using alcohol by gently rubbing. These leaves were heated for $15 \mathrm{~min}$ in $50 \mathrm{~mL}$ of distilled water at $50{ }^{\circ} \mathrm{C}$. Then the extract was filtrated with Whatman filter paper no. 1 and further filtered using vacuum filter with pore size of $0.2 \mu \mathrm{m}$. The final filtrate was stored in cool dry place for further use.

\subsection{Green Synthesis of Silver Nanoparticles}

Initially, $50 \mathrm{mM}$ of silver nitrate $\left(\mathrm{AgNO}_{3}\right)$ solution was prepared. Then plant extract was added drop wise to it under stirring. The reaction mixture became yellowish to brownish and precipitate of silver was formed. The reaction mixture was left for $30 \mathrm{~min}$ for complete reduction to silver nitrate. Then the precipitate was collected by centrifugation at $15000 \mathrm{rpm}$ for $10 \mathrm{~min}$ at $4{ }^{\circ} \mathrm{C}$. The precipitate was vacuum dried at $30{ }^{\circ} \mathrm{C}$ and the sample, i.e ET conjugated silver nanoparticle (ET-Ag NP) was stored for further studies.

\subsection{Experimental Animals}

Swiss albino male mice of 5-8 weeks old and weighing approximately $(35 \pm 2.0 \mathrm{~g})$ were procured from a CPCSEA approved animal house (Registration No. 50/CPCSEA/1999) and randomly divided into three groups of six mice each $(n=6)$ and all of them received standard laboratory diet (Hindustan Lever, Kolkata) and water ad libitum. The animals were housed in large clean polypropylene cages in a temperaturecontrolled room $\left(20 \pm 2{ }^{\circ} \mathrm{C}\right)$ with relative humidity (45-60\%) under $12 \mathrm{~h}$ light and dark cycles during the whole study period. Prior to experimentation, acclimatization was done for 7 days. The animals were maintained according to the guidelines recommended by Committee for the Purpose of Control and Supervision of Experiments on Animals (CPCSEA), Chennai, India and approved by the Institutional Animal Ethics Committee (IAEC) (Approval No. AEC/PHARM/1503/03/2015 dated 30.11.15). All procedures complied with the Declaration of Helsinki, as revised in 1996. 


\subsection{Characterization of Synthesized ET-Ag NP}

UV-Vis spectra of the aqueous solutions of synthesized Ag NPs were recorded in $\lambda 25$ spectrophotometer (Perkin Elmer, Germany) within the range of 200 to $800 \mathrm{~nm}$. XRD patterns of the synthesized materials were analyzed in the range of $2 \theta$ from $25^{\circ}$ to $80^{\circ}$ using powder diffractometer, Model D8, BRUKER AXS, using $\mathrm{CuK} \alpha$ radiation $(\alpha=0.15425 \mathrm{~nm})$. For this purpose, solution of Ag NPs was repeatedly drop casted on glass slides to make a thick coating of Ag NPs.

\subsection{Appraisal of Acute Toxicity}

Acute toxicity studies of the nanoconjugate was carried out in mice by using Organization for Economic Co-operation and Development (OECD) guideline 425 [9]. Before administration of a single dose of the test samples, the mice were deprived of food for $3 \mathrm{~h}$. Doses of 2000 and 5000 $\mathrm{mg} / \mathrm{kg}$ of the test samples were given to Group II and Group III respectively, whereas Group I served as vehicle control and were orally administered $2 \mathrm{~mL}$ of distilled water. The respective doses were suspended in water and were administered orally.

The mice were observed after every 30 min post nanocomposite treatment for $2 \mathrm{~h}$. Once daily cage side observations included changes in skin, fur, eyes, mucous membrane (nasal), autonomic (salivation, lacrimation, perspiration, piloerection, urinary incontinence, and defecation) and central nervous system (drowsiness, gait, tremors and convulsion) changes. Mortality, if any, was determined over a period of 2 weeks. After completion of the treatment, the animals were sacrificed by cervical dislocation and necropsied to facilitate gross pathological examination of organs.

\subsection{Clinical Observation}

The treated animals were observed for mortality (twice daily) and the clinical signs were recorded to note the onset, duration and reversal (if any) of toxic effect at 2, 4, 6 and 8 hours after the administration of last substances and once daily thereafter for 14 days. The routine cage side observations included changes in skin and fur, eye and mucus membrane, somatomotor activity, general behavior pattern were noted. Miscellaneous sings like arching of the back, alopecia, wound, nasal discharge, lacrimation and loose stool were also recorded during the observation.

\section{Results and Discussion}

\subsection{Characterization of NPS}

The UV-Vis spectra of both chemically synthesized and green synthesized nanomaterials (Fig. 1) showed absorption band between wavelength range $300-500 \mathrm{~nm}$, with a peak at $430 \mathrm{~nm}$, conforming presence of Ag NPs in the solution. In case of ET conjugated AgNPs (ET-Ag $\mathrm{Nps)}$ the absorption spectra remained almost same with a slight blue shift in the absorption maxima.

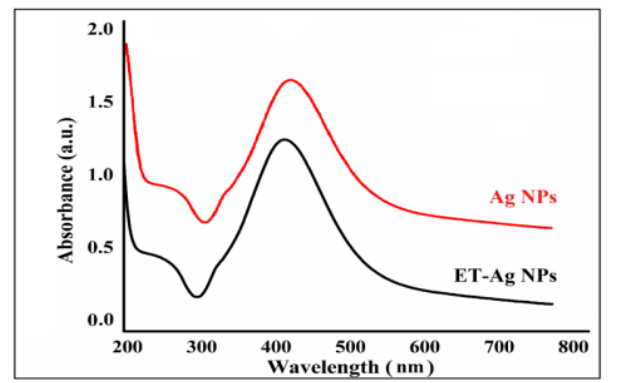

Fig. 1 UV-Vis spectra of both chemically synthesized and green synthesized nanomaterials

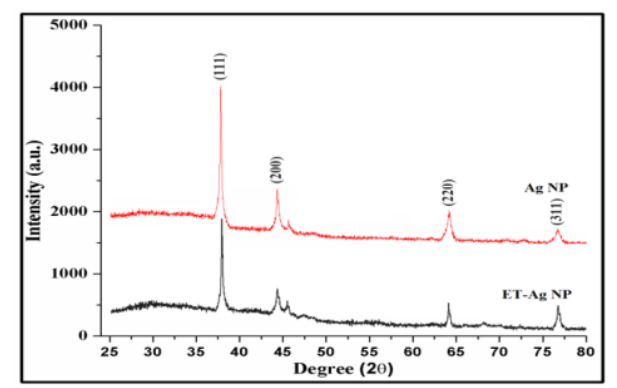

Fig. 2 XRD patterns of the synthesized materials

https://doi.org/10.30799/jnst.125.18040402
The XRD pattern of the synthesized nanomaterial (Fig. 2) showed diffraction peaks at $2 \theta=38.2^{\circ}, 44.6^{\circ}, 64.6^{\circ}$ and $77.3^{\circ}$, which respectively corresponded to (111), (200), (220) and (311) planes of pure silver. All peaks were duly assigned by using JCPDS file no. 04-0783 pertaining to pure silver.

\subsection{Behavioural Observations and General Appearance}

The behavioral parameters of animals were observed 2, 4, 6 and $8 \mathrm{~h}$ after the administration of the nanocomposite according to the standard protocol. No marked changes were observed in the wellness parameters observed. There were no mortality and all the mice survived the 14 day study period.

\subsection{Body Weight}

Tables 1 and 2 show the change observed before and after administration of the nanocomposite, there were very slight increase in body weight of the animals but were statistically insignificant.

Table 1 Effect of Ag NPs on the body weight of mice at 2,000 mg/kg dose

\begin{tabular}{llll}
\hline Mice & 0Day & $7^{\text {th }}$ day & $14^{\text {th }}$ day \\
\hline Control & $24.1 \pm 2.74$ & $27.5 \pm 2.08$ & $30.1 \pm 0.97$ \\
$2000 \mathrm{mg} / \mathrm{kg}$ body wt & $24.4 \pm 1.31$ & $25.1 \pm 2.24$ & $27.8 \pm 1.12$ \\
\hline
\end{tabular}

Table 2 Effect of Ag NPs on the body weight of mice at 5,000 mg/kg dose

\begin{tabular}{llll}
\hline Mice & 0Day & $7^{\text {th }}$ day & $14^{\text {th }}$ day \\
\hline Control & $24.2 \pm 2.02$ & $27.6 \pm 1.61$ & $30.9 \pm 0.95$ \\
$5000 \mathrm{mg} / \mathrm{kg}$ body wt. & $24.1 \pm 0.98$ & $25.8 \pm 1.05$ & $27.0 \pm 1.33$ \\
\hline
\end{tabular}

\subsection{Behavioral Observations and General Appearance}

In this study the behavioral parameters and appearance of animals after drug administration is an indicator of the toxicity of the test drug. The behavioral patterns of animals were observed in $2 \mathrm{~h}, 4 \mathrm{~h}, 6 \mathrm{~h}$ and $8 \mathrm{~h}$ interval and followed by $14 \mathrm{~h}$ after the administration. The behavioral parameters and appearance was observed according to the standard protocol. No significant changes were observed in wellness parameters used for evaluation of toxicity. Skin, fur, eyes, mucous membrane, behavioral pattern, salivation and sleep pattern parameters of the treated animals were found to be normal (Tables 3 and 4). No toxic symptom or mortality was observed in any mice. All treated mice lived up to 14 days after the administration of Ag NPs.

Table 3 Clinical observations of mice at 2,000 mg/kg dose of Ag NPs

\begin{tabular}{|c|c|c|c|c|c|c|}
\hline Signs and symptoms & Mice 1 & Mice 2 & Mice 3 & Mice 4 & Mice 5 & Mice 6 \\
\hline Behavior & Normal & Normal & Normal & Normal & Normal & Normal \\
\hline Somatomotor activity & Normal & Normal & Normal & Normal & Normal & Normal \\
\hline Skin and Fur & Normal & Normal & Normal & Normal & Normal & Normal \\
\hline $\begin{array}{l}\text { Eyes and mucous } \\
\text { membranes }\end{array}$ & Normal & Normal & Normal & Normal & Normal & Normal \\
\hline Salivation & Absent & Absent & Absent & Absent & Absent & Absent \\
\hline Diarrhoea & Absent & Absent & Absent & Absent & Absent & Absent \\
\hline Tremors/ convulsions & Absent & Absent & Absent & Absent & Absent & Absent \\
\hline Death & Nil & Nil & Nil & Nil & Nil & Nil \\
\hline Other symptoms & Nil & Nil & Nil & Nil & Nil & Nil \\
\hline
\end{tabular}

Table 4 Clinical observations of mice at 5,000 mg/kg dose of Ag NPs

\begin{tabular}{lllllll}
\hline Signs and symptoms & Mice 1 & Mice 2 & Mice 3 & Mice 4 & Mice 5 & Mice 6 \\
\hline Behavior & Normal & Normal & Normal & Normal & Normal & Normal \\
Somatomotor activity & Normal & Normal & Normal & Normal & Normal & Normal \\
Skin and Fur & Normal & Normal & Normal & Normal & Normal & Normal \\
$\begin{array}{l}\text { Eyes And mucous } \\
\text { membranes }\end{array}$ & Normal & Normal & Normal & Normal & Normal & Normal \\
Salivation & & & & & & \\
Diarrhoea & Absent & Absent & Absent & Absent & Absent & Absent \\
Tremors/ convulsions & Absent & Absent & Absent & Absent & Absent & Absent \\
Death & Nil & Absent & Absent & Absent & Absent & Absent \\
Other symptoms & Nil & Nil & Nil & Nil & Nil & Nil \\
\hline & & & & & Nil & Nil \\
\hline
\end{tabular}

\subsection{Necropsy}

All the animals were sacrificed on day 14 and necropsied. Body cavities (cranial, thoracic, abdominal and pelvic) did not reveal any lesions nor any inflammation or any abnormalities (Table 5). 
Table 5 Effect of NPs on the necropsy of mice at 2,000 \& $5000 \mathrm{mg} / \mathrm{kg}$ dose

\begin{tabular}{lll}
\hline Animals & Observed lesions $(2000 \mathrm{mg} / \mathrm{kg})$ & Observed lesions $(5000 \mathrm{mg} / \mathrm{kg})$ \\
\hline 1 & Nil & Nil \\
2 & Nil & Nil \\
3 & Nil & Nil \\
4 & Nil & Nil \\
5 & Nil & Nil \\
6 & Nil & Nil \\
\hline
\end{tabular}

\section{Conclusion}

There was no change in the general health of the animals throughout the study. The results indicate that the nanocomposite did not exhibit any toxicity. These findings may facilitate the development of safe and efficient Ag-ET nanoconjugate as an effective therapy against glucose mediated health disorders.

\section{References}

[1] E.C. Peterson, L.E. Ewing, Nanomedicine: going small to beat the high, Nature Nanotechnol. 11 (2016) 580-581.

[2] N. Polley, S. Saha, A. Adhikari, S. Banerjee, S. Darbar, S. Das, S.K. Pal, Safe and symptomatic medicinal use of surface-functionalized $\mathrm{Mn}_{3} \mathrm{O}_{4}$ nanoparticles for hyperbilirubinemia treatment in mice, Nanomed. 10 (2015) 2349-2363.

[3] V. Orel, A. Shevchenko, A. Romanov, M. Tselepi, T. Mitrelias, C.H. Barnes, et al., Magnetic properties and antitumor effect of nanocomplexes of iron oxide and doxorubicin, Nanomed. Nanotechnol. Biol. Med. 11 (2015) 47-55.

[4] J.H. Park, S. Lee, J.H. Kim, K. Park, K. Kim, I.C. Kwon, Polymeric nanomedicine for cancer therapy, Prog. Polym. Sci. 33 (2008) 113-137.
[5] Y. Li, T.Y. Lin, Y. Luo, Q. Liu, W. Xiao, W. Guo, et al., A smart and versatile theranostic nanomedicine platform based on nanoporphyrin, Nature Comm. 5 (2014) 4712-1-15.

[6] A. Cirstoiu-Hapca, F. Buchegger, L. Bossy, M. Kosinski, R. Gurny, F. Delie, Nanomedicines for active targeting: physico-chemical characterization of paclitaxel-loaded anti-HER2 immunonanoparticles and in vitro functional studies on target cells, Eur. J. Pharm. Sci. 38 (2009) 230-237.

[7] A. Kunzmann, B. Andersson, T. Thurnherr, H. Krug, A. Scheynius, B. Fadeel, Toxicology of engineered nanomaterials: focus on biocompatibility, biodistribution and biodegradation, Biochim. Biophys. Acta Gen. Sub. 1810 (2011) 361-373.

[8] P. Dandekar, R. Dhumal, R. Jain, D. Tiwari, G. Vanage, V. Patravale, Toxicological evaluation of $\mathrm{pH}$-sensitive nanoparticles of curcumin: acute, sub-acute and genotoxicity studies, Food Chem. Toxicol. 48 (2010) 2073-2089.

[9] D.G. Olmedo, D.R. Tasat, M.B. Guglielmotti, R.L. Cabrini, Effect of titanium dioxide on the oxidative metabolism of alveolar macrophages: an experimental study in rats, Jour. Biomed. Mater. Res. A 73 (2005) 142-149.

[10] A.R.M. Syahmi, S. Vijayarathna, S. Sasidharan, L.Y. Latha, Y.P. Kwan, Y.L. Lau, et al., Acute oral toxicity and brine shrimp lethality of Elaeis guineensis Jacq.,(oil palm leaf) methanol extract, Molecules 15 (2010) 8111-8121.

[11] S. Becker, Nanotechnology in the marketplace: how the nanotechnology industry views risk, Jour. Nanopart. Res.15 (2013) 1426-1428.

[12] G.D. Venkatasubbu, S. Ramasamy, G. Avadhani, V. Ramakrishnan, J. Kumar Surface modification and paclitaxel drug delivery of folic acid modified polyethylene glycol functionalized hydroxyapatite nanoparticles, Powder Technol. 235 (2013) 437-442.

[13] S. Darbar, S. Saha, K.S. Pramanik, A.K. Chattopadhyay, Preliminary acute oral toxicity study of a newly developed herbal formulation, World J. Pharm.l Res. 7 (2018) 924-930.

[14] S. Parasuraman, Toxicological screening, Jour. Pharmacol. Pharmacother. 2 (2011) 74-79.

[15] R.W. Setzer, C.A. Kimmel, Use of NOAEL, benchmark dose, and other models for human risk assessment of hormonally active substances, Pure Appl. Chem. 75 (2003) 2151-2158. 